\title{
Rethinking Human Ethology
}

\section{A Response to Some Recent Critiques}

\author{
Laura Betzig \\ Evolution and Human Behavior Program, University of Michigan, Ann \\ Arbor, Michigan
}

As Tinbergen pointed out a quarter of a century ago, ethology employs many levels of investigation. Studies of psychological adaptations, and of current fitness functions, are two of them. All of these investigations are valid, none is intrinsically most important, and each can be enhanced by the others.

KEY WORDS: Adaptation; Fitness; Human evolution.

\section{6 here's more than one way to skin a grasshopper."}

\section{WHO ANTICIPATED SUCH A STATEMENT}

Tinbergen (1963), on the occasion of Lorenz's 60th birthday, wrote his famous paper "On Aims and Methods of Ethology." In it, he distinguished four related fields of ethology, or "the biological study of behavior," as he succinctly defined it. They were: 1) the study of causation, meaning the search for the the physiological mechanisms underlying any given behavior pattern; 2) the study of survival valuc, or of its fitness function; 3 ) the study of ontogeny, or the development of the behavior over the individual's life history; and 4) the study of evolution, or of its phylogenetic history. In his discussion of the second, he wrote:

In the post-Darwinian era, a reaction against uncritical acceptance of the selection theory set in. ... It was a reaction against the habit of making uncritical guesses about the survival value, the function, of life processes and structures. This reaction, of course healthy in itself, did not (as one might expect) result in an attempt to improve methods of studying survival

Received November 16, 1987; revised January 11, 1989.

Address reprint requests to: Laura Betzig, Ph.D., Evolution and Human Behavior Program, 1524 Rackham, University of Michigan, Ann Arbor, MI 48109. 
value; rather it deteriorated into lack of interest in the problem-one of the most deplorable things that can happen to a science. Worse, it even developed into an attitude of intolerance: even wondering about survival value was considered unscientific. (p. 417)

In the quarter century since Tinbergen made that statement, there has been an explosion in the investigation of the survival, or fitness, function of animal behavior (see, e.g., Alexander and Tinkle 1981; Clutton-Brock 1988; Krebs and Davies 1978) Following that precedent, a start has been made in studying the function of human behavior (see, e.g., Alexander and Tinkle 1981; Betzig et al. 1988; Chagnon and Irons 1979). Critical voices have continued to respond. With the exception that the phrase "fitness" should replace "survival value," Tinbergen's statement is on the mark today. This essay responds in turn.

\section{WHY STUDIES OF FUNCTION BEAR ON THE PROBLEM OF ADAPTATION}

The fact that a behavior promotes fitness in the present does not, by itself, make the case that such a behavior promoted fitness in the past. In other words, fitness need not be an outcome of selection (see, e.g., Gould and Lewontin 1979; Kitcher 1985; Symons 1987). As Tinbergen pointed out, a demonstration of the fitness effects of any trait is strictly no more than a demonstration of the current selection pressure for maintaining that trait. "What selection pressure must have been responsible in the past for the moulding of the character studied is speculative, however probable it often is" (Tinbergen 1963, p. 429).

At least three lines of evidence, however, can be used to strengthen the inference of fitness-promoting cause from fitness-promoting effects. Tinbergen (1963) himself suggested that one line of support for such an inference would come from evidence that relevant environmental constraints had remained strong enough for long enough to select for a trait. Paleontological evidence, and ethnographic reconstruction, would be relevant here (see, e.g., Lee and DeVore 1968).

Another line of evidence supporting an inference of adaptive cause from effects is data on the existence of specific mechanisms or ontogenies, i.e., on any of the "missing links" (e.g., Cosmides and Tooby 1987) in the development of phenotypes from genes. An example makes this point. Hamilton argued in 1964 that apparent altruism may evolve where it sufficiently enhances the fitness of close genetic kin. Soon after that, many animal behaviorists looked for, and found, correlations between altruistic behaviors and inclusive fitness effects (e.g., Sherman 1977). Following those studies of function, many researchers studied the ontogeny of "kin recognition," looking for a mechanism by which kin might come to recognize, and eventually to favor, close kin (e.g., Holmes and Sherman 1983). Evidence sup- 
porting the existence of such ontogenies, and such mechanisms, has strengthened the inference of cause from effects. So would heritability studies, showing that genes play a role in the development of mechanisms (e.g., Arnold 1988). Heritability studies are likely to make such a contribution where selection has not been so strong as to eliminate genetic variance underlying the trait in question.

A third way to strengthen the inference of adaptive cause from effects is simply to argue against alternative theories. If fitness-promoting traits are not products of past selection, what else might have produced them? An exhaustive list of alternatives includes the following. First are the random forces in evolution, including mutation and drift, which provide the raw material on which selection must act. Second is the nonrandom force in evolution, i.e., selection, which might have favored a trait because it performed a different function, or as a side effect of action on another part of the organism. Exaptation and allometry or pleiotropy would be included here (see, e.g., Gould and Lewontin 1979; Gould and Vrba 1982). Third is what might be called random environmental forces. Learning errors might be included here. Fourth are nonrandom environmental forces. "Culture" would probably belong here (see, e.g., Boyd and Richerson 1985; CavalliSforza and Feldman 1981; Durham 1979).

Of these alternatives, it has been convincingly argued that the first, genetic drift, is highly unlikely to produce apparent adaptation (e.g., Dawkins 1986); the same probabilities should apply to the third alternative, environmental "drift." The stronger alternatives, the nonrandom genetic and environmental forces, can both be viewed as byproducts of selection. Nonrandom genetic changes like pleiotropy amount to compromises on one part of an organism to accommodate selection operating on another part. In a similar way, culture appears to be chosen and changed by individuals who do so in interests that are products of natural selection (e.g., Alexander 1987); some of these choices, though, inevitably compromise others. It isn't hard to think of maladaptive side effects of selection. Senescence, for instance, has been explained as a pleiotropic side effect of selection for reproductive vigor early in life (Williams 1957). In a roughly analogous way, pollution might be explained as a cultural side effect of selected for traits that, at least until recently, have increased resource access overall. It is, on the other hand, much more difficult to think up fitness-enhancing side effects of selected traits. In other words, each of these nonrandom alternatives, like the random ones, seems much less likely to produce fitness-promoting than fitness-reducing actions.

This bears repeating. If "culture," along with other forces, has not often led behaviors off the adaptive track, then it is even less likely that "culture," or any other alternative, has led them on track. Alternative forces, even the nonrandom ones, never completely converge with the forces of selection. As a result, any of these alternative forces is more likely to have led behaviors off the adaptive track than on. Spurious inferences of a past cor- 
relation between behavior and fitness from a present one are unlikely. In other words, Tinbergen (1963) was right to use both the words "speculative" and "probable" in his statement about the inference of past selection from present function. The inference is speculative, because each of these alternative explanations exists, so that the odds that present fitness is the product of past selection are never $100 \%$. At the same time, the odds that any alternative force produced a correlation between behavior and fitness are always less than the odds that they were produced by selection. Selection is the single most probable cause.

\section{WHERE TO FIND A FEW EXAMPLES}

Symons (1987) has said that studies of function "do not test any hypothesis about evolutionary processes or the human nature that these processes have produced.' But they do. One reason why Ifaluk chiefs may fail to turn status into fitness (Betzig 1988b), or Yanomamö kin terms may not be fudged in ways that increase access to mates (Chagnon 1988), or Tibetan polyandry might not be an adaptive strategy (Crook and Crook 1988), is that natural selection has been overestimated as a factor in evolution. The same is true of any prediction about function. Just as four alternatives to selection can explain an apparent fit between behavior and reproductive success, four alternatives can explain an apparent lack of fit. These include the possibilities that natural selection: 1) failed to compensate for random genetic effects, e.g., drift; 2) failed to compensate for nonrandom genetic effects, e.g., pleiotrophy; 3) failed to accommodate random environmental fluctuations, i.e., failed to generate adequate plasticity; and 4) failed to keep pace with nonrandom environmental change, e.g., because environmental change has been too sudden or strong. Research may bear any alternative out.

Following Dawkins (1982; pp. 27-28), Symons confuses the issues of fitness cause and effect in his critique of Crook and Crook's (1988) study of Tibetan polyandry (see Turke 1984). As Symons (1989) points out, polyandry itself is an adaptation only if polyandrous people have spread genes for polyandry over the course of evolution. At the same time, polyandry is adaptive if it presently promotes the fitness of its practitioners (see discussions of adaptation in Burian 1983; Caro and Borgerhoff Mulder 1987; Williams 1966). This Crook and Crook's study suggests that it does.

As Symons says, it is most unlikely that finding adaptive behaviors like power exploitation, kin term manipulation, and polyandry imply the existence of adaptations specifying "keep the extra fish," "reclassify women as cross cousins," or "marry your brother's wife." That doesn't mean that every one of those behaviors isn't likely to have been produced by a number of adaptations, including strong psychological mechanisms promoting resource gathering, mate winning, and assisting close kin. Unlike polyandry, or cross-cousin marriage, or redistribution of fish found on Ifaluk reefs, each 
of these behaviors probably had an important effect on the fitness of huntergatherers over the long haul of human evolution. If people who performed them better or worse did so in part because of differences in underlying mechanisms, tied in turn to differences in their genes, then those genes should have been favored by natural selection. It is highly likely that each of these complex behavior patterns is produced by a number of well-integrated adaptations (see, e.g., Alexander 1987; Gould and Lewontin 1979; Mayr 1983). Evidence supporting the existence of such mechanisms (among other forms of evidence) will strengthen the conclusion that, e.g., Tibetan polyandry currently promotes reproductive success because relevant behaviors did so in the past.

\section{WHAT CAN AND CAN'T BE DONE}

To another group of critics, studies of behavior in any organism--from grasshoppers to humans - are of value only in so far as they are, in effect, studies of its underlying nature. This group is large (see, e.g., Barkow 1984, 1989; Cosmides and Tooby 1987, 1989; Kitcher 1985, 1989; Daly and Wilson 1988; Symons 1987, 1989; Wilson 1978). Methods should, however, be judged better or worse in light of the specific problem they are meant to solve (see also Sherman 1988).

For one thing, understanding each of these-human nature and human behavior--should contribute to our understanding of the other. Contrary to several suggestions (e.g., Cosmides and Tooby 1987, 1989; Symons 1987, 1989; Tooby and Cosmides 1989), although the study of underlying adaptations has often been considered a forbiddingly difficult cndeavor (c.g., Caro and Borgerhoff Mulder 1987; Gould and Lewontin 1979; Williams 1966) it has seldom if ever been considered a trivial matter. As Tooby and Cosmides (1989) and others point out, knowledge of specific mechanisms should predict behavior more accurately than general predictions about its adaptive function. At the same time, finding out what behaviors currently promote reproductive success leads directly to questions about underlying mechanisms. Knowledge of who we are illuminates what we do; and knowledge of what we do illuminates who we are. On the other hand, it is because there is often no simple one-to-one correspondence between mechanism and behavior pattern that studies of function are not equivalent to studies of causation. Most complex - often the most interesting-behavior patterns, in grasshoppers and, especially, in humans, are likely to be produced by the interaction of a number of underlying adaptations (cf., e.g., Mayr 1983). Certainly this is true of behaviors like political exploitation, kin term manipulation, and polyandry. It might even be the case with attractiveness judgments (see Symons 1989), incest avoidance (e.g., Kitcher 1989), and social contract logic (Cosmides and Tooby 1989); all these have been considered independent adaptations. 
For another thing, studies of causation and function can bring different lines of evidence to bear on the theoretical problem of adaptation by natural selection. Studies of psychology make part of the case for adaptation by showing evidence of design; studies of fitness make part of the case for adaptation by showing that behaviors currently promote, or are likely to promote, fitness. Again, contrary to what many have recently stated or implied, both the structure argued to be a product of fitness differences (in studics of causation), and the bchavior argued to cnhance fitness differences (in studies of function), may be the effect of a constellation of adaptations (see Mayr 1983); and each of these may have been produced in turn by a variety of selective pressures over the course of evolution (see Gould and Vrba 1982).

Finally, much recent criticism of function can be applied to studies of causation: both studies of nature and of behavior come with certain problems. One is that any of the relatively simple behaviors named aboveattractiveness judgments, incest avoidance, and social contract logic-might seem as easily predicted by common sense as any of the complex behaviors-the exploitation of power, the manipulation of kinship terminology, and polyandry - listed earlier (contrast Cosmides and Tooby 1987, p. 277; see also Barkow 1984, 1989; Kitcher 1985, 1989; Symons 1987, 1989). However, neither predictions about causation nor about function need overlap completely with common sense. Because common sense follows from common experience, it can sometimes "predict" outcomes without recourse to theories of evolution. It is also true that common sense-which Kitcher (1985) elevated to the status of "folk psychology" - sometimes cannot. One reason is that people's experiences are limited. Another reason, which follows itself from Darwinism, is that we may have evolved to excel at selfdeception (e.g., Alexander 1975). Because few paid ethologists have lived in traditional cultures, and because we seem so adept at e pluribus unum deceptions in our own, common sense is sometimes at odds with the expectation that power will be exploited (Betzig 1986a, 1988b), and often at odds with the finding that exploitation is translated into reproduction (Betzig 1986b, 1988a,b). Means by which the powerful achieve reproductive ends can be especially surprising. As Chagnon (1988), for example, has pointed out, what structural anthropologist would have thought to find out that Yanomamö men manipulate kin terms to expand their pools of mates? As Symons (1989) himself points out, such predictions "frequently turn out to be more accurate than other social science predictions."

Another common problem is that both studies of causation and function can be led astray by wrong assumptions about environmental constraints. Mistaken assumptions about past conditions can result in mistaken predictions about the existence of underlying adaptations. And if current environmental conditions are too novel, then mechanisms may fail to develop, or to operate, as they did in the past. Failures in development will lead to faulty predictions about the existence of adaptations, and failures in operation will 
lead to mistaken predictions about what behaviors will be adaptive (contrast Symons 1979). As Daly and Wilson (1984) point out, failure to bear out predictions about function can sometimes lend insight into underlying adaptations. This will be so if environmental conditions eliciting ontogeny are enough like those of the evolutionary past, while those eliciting behavior later on are not.

A third common "problem" is that predictions about both nature and behavior will be wrong if any of the alternative evolutionary forces listed above has swamped selection. If alternative evolutionary forces have been too strong, looked-for adaptations and behaviors will be imperfect, or even nonexistent.

\section{HOW GENES FIT IN}

Again, it isn't always easy to argue that behaviors currently promote fitness because they did so in the past. In order to avoid those problems, another line of criticism has taken the position that studies of cause be divorced from studies of effect. In one such critique, Caro and Borgerhoff Mulder (1987) concluded that "identification of adaptations according to . . the reproductive benefits conferred on bearers, without any assumptions about the trait's function in the past, guides a more cautious approach to the study of behavior" (p. 66, emphasis added; see also p. 69). Taken to its extreme, this can be cautious to the point of taking the history out of natural history. That might raise two important problems. First, a history of natural selection makes possible the prediction that traits will not be randomly related to their fitness effects. Without invoking it, ethology becomes a purely inductive enterprise. Second, Caro and Borgerhoff Mulder's approach leaves unanswered the important question of origin. Without reconstructing the selective pressures that might have shaped behaviors, gathering evidence on the existence of underlying mechanisms themselves likely to have been shaped by evolution, or arguing against alternative theories, we may never make the case that the reason behaviors promote fitness in the present is because they did so in the past. $\Lambda$ s Caro and Borgerhoff Mulder themselves point out, if adaptive behavior "is not viewed as a product of selection, the need to measure reproductive success might be called into question"' (p. 67). They counter that it may be enough that "with information on the different reproductive consequences of different behavior patterns, we are in some position to make predictions about the distribution of morphological and behavioral traits in present and future generations"' (ibid; cf. Clutton-Brock and Harvey 1979). But if we have trouble reconstructing selective environments in the past - a major difficulty, they point out, with studies of evolution-then how much more trouble will we have in predicting their future course? How interesting is it to know that traits currently correlate with fitness, with no idea as to whether that correlation is a product of selection, 
or how substantially such selection may be maintained in future generations? To many, studies of fitness in the present are of interest because they try to answer the "why" question: because they help make the case that current actions are outcomes of natural selection (this agrees with Borgerhoff Mulder 1987).

Caro and Borgerhoff Mulder's advocacy of studies of fitness effects without causes is sometimes echoed in other places. Dunbar (1988a p. 167; see also Dunbar 1984, 1988b), for example, wrote in another critique that "sociobiology is concerned centrally with the consequences of behavior in terms of gene propagation and it is a serious mistake to assume that this necessarily implies anything about the genetic control of ontogeny or, more importantly, of behavior itself." Statements like these can exonerate evolution into oblivion. Again, a history of selection-of gene frequency change-is by far the most likely cause of, for instance, sex-biased investment in Serengeti cheetah and Kenyan Kipsigis (Borgerhoff Mulder 1989; Caro 1987), and of facultative mating tactics in Gelada baoons (Dunbar 1984), behaviors that their investigators have taken pains to show promote fitness effects (see also Alexander 1987).

A plausible explanation, then, for the fact that behaviors currently serve an adaptive function is that genes facilitating such behaviors were selected in the past (see, e.g., Dawkins 1986). That, as Dunbar is undoubtedly trying to point out (1988a, p. 167), tells us nothing about how easy or hard it may be to change them (e.g., Betzig 1986b, 1988a). Studies of Tinbergen's fourth form of ethology, ontogeny, are needed to know that.

\section{WHEN NOT TO GIVE UP}

Toward the end of his famous paper, Tinbergen (1963, p. 430) assessed, in part, the value of Lorenz's work by observing that "students of human behaviour are showing a growing interest in ethological methods." That interest has continued to grow, prompting a number of recent critiques, and this response. Twenty-five years after Tinbergen, studies of function both inform and are informed by studies of causation, ontogeny, and evolution.

Thanks are offered to the University of Michigan Department of Social Psychology for NIMH funding during initial writing; to Tim Caro and Monique Borgerhoff Mulder, John Tooby and Leda Cosmides, Margo Wilson and Martin Daly, Randy Thornhill and Nancy Wilmsen Thornhill, Richard Alexander, and especially Donald Symons for very generously providing a stream of manuscripts, letters, and discussion; and to Bobbi Low, Joe Manson, Pat Overby, Barb Smuts. Paul Turke, other members of the University of Michigan Evolution and Human Behavior Program, Nicholas Blurton Jones, Michael McGuire, and anonymous reviewers for criticism. Special thanks to Steve Frank for an admonition to read Tinbergen. 


\section{REFERENCES}

Alexander, R.D. The search for a general theory of behavior. Behavioural Science, 20: 77100,1975

- The Biology of Moral Systems. Hawthorne, NY: Aldine-de Gruyter, 1987.

and Tinkle, D. Natural Selection and Social Behavior: Recent Research and New Theory. New York: Chiron Press, 1981.

Arnold, S. The need for genetical studies in behavioral ecology. Paper read at Second International Behavioral Ecology Conference, Simon Fraser University, 1988.

Barkow, J. The distance between genes and culture. Journal of Anthropological Research 40: 367-379, 1984.

- The elastic between genes and culture. Ethology and sociobiology 10: 111-129, 1989.

Betzig, L. L. Despotism and Differential Reproduction: A Darwinian View of History. Hawthorne, NY: Aldine de Gruyter, 1986a.

- Valuting, leaping, skipping, and trudging ambition. Quarterly Review of Biology 61 : $517-$ 521, 1986b.

- Mating and parenting in Darwinian perspective. In Human Reproductive Behavior: A Darwinian Perspective, L. Betzig, M. Borgerhoff Mulder, and P. Turke (Eds.). Cambridge: Cambridge University Press, 1988a, pp. 3-20.

- Redistribution: Equity or exploitation? In Human Reproductive Behavior: A Darwinian Perspective, L. Betzig, M. Borgerhoff Mulder, and P. Turke (Eds.). Cambridge: Cambridge University Press, 1988b, pp. 49-63.

- Borgerhoff Mulder, M., and Turke, P. Human Reproductive Behavior: A Darwinian Perspective. Cambridge: Cambridge University Press, 1988.

Borgerhoff Mulder, M. Adaptation and evolutionary approaches to anthropology. Man 22: 2541, 1987.

Reproductive consequences of sex-biased inheritance. In Comparative Socioecology. V. Standen and R. Foley (Eds). Oxford: Blackwell, 1989.

Boyd, R., and Richerson, P. Culture and the Evolutionary Process. Chicago: University of Chicago Press, 1985.

Burian, R. Adaptation. In Dimensions of Darwinism, M. Grene (Ed.). Cambridge: Cambridge University Press, 1983, pp. 287-314.

Caro, T. Sex biased investment in Serengeti cheetah. Paper read at School of Natural Resources, University of Michigan, Ann Arbor, MI, 1987.

Caro, T., and Borgerhoff Mulder, M. The problem of adaptation in the study of behavior. Ethology and Sociobiology 8: 61-72, 1987.

Cavalli-Sforza, P., and Feldman, F. Cultural Transmission and Evolution: A Quantitative Approach. Princeton: Princeton University Press, 1981.

Chagnon, N. A. Male Yanomamö manipulations of kinship classifications of female kin for reproductive advantage. In Human Reproductive Behavior: A Darwinian Perspective, L. Betzig, M. B. Mulder, and P. Turke (Eds.). Cambridge: Cambridge University Press, 1988, pp. 23-48.

- - and Irons, W. Evolutionary Biology and Human Social Behavior: An Anthropological Perspective. North Scituate, MA: Duxbury Press, 1979.

Clutton-Brock, T. H. Reproductive Success. Chicago: University of Chicago Press, 1988.

Clutton-Brock, T., and Harvey, P. Comparison and adaptation. Proceedings of the Royal Society of London, $B$ 205: 547-565, 1979

Cosmides, L., and Tooby, J. From evolution to behavior: Evolutionary psychology as the missing link. In The Latest on the Best: Essays on Evolution and Optimality, $\mathrm{J}$ Dupre (Ed.). Cambridge, MA: MIT Press, 1987, pp. 277-306.

_ _ and - Evolutionary psychology and the generation of culture, part II. Case study: A computational theory of social exchange. Ethology and Sociobiology 10: 51-97, 1989.

Crook, J., and Crook, S. Tibetan polyandry: Problems of adaptation and fitness. In Human Reproductive Behavior: A Darwinian Perspective, L. Betzig, M. Borgerhoff Mulder, and P. Turke (Eds.). Cambridge: Cambridge University Press, 1988.

Daly, M., and Wilson M. A sociobiological analysis of human infanticide. In Infanticide, G. Hausfater and S. B. Hrdy (Eds.). Hawthorne, NY: Aldine, 1984, pp. 487-502. 
—.., and - . 1988. Honticide. Hawthorne, NY: Aldine, 1988.

Dawkins, R. The Extended Phenotype. San Francisco, CA: Freeman, 1982.

- The Blind Watchmaker. New York: Norton, 1986.

Dunbar, R. Reproductive Decisions: An Economic Analysis of Gelada Baboon Social Strategies. Princeton: Princeton University Press, 1984.

- Darwinising man: A commentary. In Human Reproductive Behavior: A Darwinian Perspective, L. Betzig, M. Borgerhoff Mulder, and P. Turke (Eds.). Cambridge: Cambridge University Press, 1988a, pp. 161-169.

—. Primate Social Behavior. Ithaca: Cornell University Press, $1988 \mathrm{~b}$.

Durham, W. Toward a coevolutionary theory of human hiology and culture. In Fvolutionary Biology and Human Social Behavior: An Anthropological Perspective, N. Chagnon and W. Irons (Eds.). North Scituate, MA: Duxbury Press, 1979, pp. 39-59.

Gould, S., and Lewontin, R. The Spandrels of San Marco and the Panglossian paradigm. Proceedings of the Royal Society of London B 205: 581-98, 1979.

Gould, S., and Vrba, E. Exaptation-a missing term in the science of form. Paleobiology 8: 3-15, 1982.

Hamilton, W. The genetical evolution of social behavior. Journal of Theoretical Biology, 7: 1$52,1964$.

Holmes, W., and Sherman, P. Kin recognition in animals. American Scientist 71: 46-55.

Kitcher, P. Vaulting Ambition. Cambridge, MA: MIT Press, 1985.

-. Manuscript in press, 1989.

Krebs, J. and Davies, N. B. Behavioural Ecology. Sunderland, MA: Sinauer, 1978.

Lee, R., and DeVore, I. Man the Hunter. Hawthorne, NY: Aldine, 1968.

Mayr, E. How to carry out the adaptationist program? American Naturalist 121: 324-334, 1983.

Sherman, P. W. Nepotism and the evolution of alarm calls. Science 197: 1246-1253, 1977. The levels of analysis. Animal Behaviour 36: 616-618, 1988.

Symons, D. The Evolution of Human Sexuality. New York: Oxford University Press, 1979.

- If we're all Darwinists, what's the fuss about? In Sociobiology and Psychology: Issues, Ideas, and Applications, C. Crawford, M. Smith, and D. Krebs (Eds.). Hillsdale, NJ: Erlbaum Associates, 1987.

-. A critique of Darwinian anthropology. Ethology and Sociobiology 10: 131-144, 1989.

Tinbergen, N. On aims and methods of ethology. Zeitscrift für Tierpsychologie 20: 410-433, 1963.

Tooby, J., and Cosmides, L. Evolutionary psychology and the generation of culture, part I. Theoretical considerations. Ethology and sociobiology 10: 29-49, 1989.

Turke, P. W. On what's not wrong with a Darwinian theory of culture. American Anthropologist 86:633-638, 1984.

Williams, G. C. Pleiotropy, natural selection, and the evolution of senescence. Evolution 11: 32-39, 1957.

- Adaptation and Natural Selection: A Critique of Some Current Evolutionary Thought. Princeton: Princeton University Press, 1966.

Wilson, E. O. On Human Nature. Cambridge: Harvard, 1978. 